\title{
A MATEMÁtica e OS MATEMÁticos do InSTITUTO TECNOLÓGICO DA AERONÁUTICA
}

\author{
Henrique Marins de Carvalho \\ Instituto Federal de Educação, Ciência e Tecnologia de São Paulo-IFSP-Brasil
}

(aceito para publicação em maio de 2016)

\begin{abstract}
Resumo
O Instituto Tecnológico de Aeronáutica foi criado com a missão de promover, por meio da educação, do ensino, da pesquisa e da extensão, o progresso das ciências e das tecnologias relacionadas com o Campo Aeroespacial e a formação de profissionais de nível superior nas especializações de interesse do Setor Aeroespacial em geral. A partir de obras elaboradas por profissionais vinculados ao ITA ou a respeito deles, legislações, documentos administrativos e dados biográficos de membros desta Instituição verifica-se, com especial ênfase nas duas primeiras décadas de existência (1950 e 1960), a participação do Departamento de Matemática no cumprimento da missão antes descrita. A influência do ITA no desenvolvimento das ciências e educação é identificada no processo de estabelecer um formato inédito para o ensino de Engenharia no Brasil, baseado no modelo do Massachusetts Institute of Technology (MIT). O programa de pós-graduação em Ciências é apresentado, desde suas origens até seu estabelecimento.Em sínteses biográficas, é delineado o perfil dos profissionais que atuaram nas disciplinas de Matemática, participantes de eventos de caráter acadêmico ou científico, autores de obras matemáticas e responsáveis pelo desenvolvimento da Matemática no ITA e, consequentemente no país.
\end{abstract}

Palavras-chave: Matemática, Décadas de 1950-1960 no Brasil, ITA.

\section{[THE MATHEMATICS AND THE MATHEMATICIANS OF THE TECHNOLOGICAL INSTITUTE OF AERONAUTICS]}

\author{
Abstract \\ RBHM, Vol. 16, nº31, p. 21-49, 2016


The Technological Institute of Aeronautics was created with the mission to promote, through education, teaching, research and extension, the progress of science and technology related to the Aerospace field and high level professionals training in major areas of the general Aerospace sector. The participation of the Department of Mathematics in fulfilling the mission described before is reached from works produced by professionals linked to the ITA or about them, laws, administrative documents and biographical data of members of this institution, with particular emphasis on the first two decades of existence (1950 and 1960), The influence of the ITA in the development of science and education is identified in the process of establishing a unique format for engineering teaching in Brazil, based on the Massachusetts Institute of Technology (MIT). The graduate program in Science is presented, from its origins to its establishment. In biographical synthesis is outlined the profile of the professionals who worked in the mathematical disciplines, members of academic or scientific events, authors of mathematical works and responsible for the development of mathematics in the ITA and consequently in the country.

Keywords: Mathematics, Decades of 1950-1960 in Brazil, Technological Institute of Aeronautics (ITA).

\section{Apresentação}

O Instituto Tecnológico de Aeronáutica (ITA) é a primeira instituição de ensino e pesquisa em Engenharia Aeronáutica no Brasil e possui um poder de perpetuação de seus ideais, relacionando o passado com o presente, sintetizando as esperanças e expectativas projetadas pela comunidade que o planejou e construiu.

Le Goff (1996, p. 536) define o binômio monumento/documento como "a montagem, consciente ou inconsciente, não só da história, da época e da sociedade que o produziram, mas também das diversas épocas sucessivas durante as quais ele continuou a existir e a ser manipulado". A partir desse conceito, identificamos o ITA como um monumento na História das Instituições e na História da Matemática no Brasil.

$\mathrm{O}$ presente trabalho se dedica a realizar uma representação do monumento ITA, a partir de seus elementos constituintes, no desenvolvimento da Ciência (e particularmente da Matemática) no Brasil. Santos (2011, p. 28) afirma, a respeito do conceito de representação, que a etimologia do verbete indica uma origem latina, oriunda do vocábulo repraesentare que significa "tornar presente". Ao destacar a importância dos matemáticos que atuaram no ITA em suas primeiras décadas de existência e da Matemática no estabelecimento de seus cursos, ensejamos trazer ao presente a história desta Instituição.

\section{O Instituto Tecnológico De Aeronáutica}


O Ministério da Aeronáutica foi criado por ato ${ }^{1}$ do Presidente da República Getúlio Vargas, em 20 de janeiro de 1941, unificando os departamentos de atividades aeronáuticas já existentes nos Ministérios do Exército (Diretoria de Aeronáutica do Ministério da Guerra), da Marinha (Diretoria de Aviação do Ministério da Marinha) e de Viações e Obras Públicas (Departamento de Aeronáutica Civil).

Responsável por administrar tática e economicamente todas as atividades associadas à Aeronáutica brasileira, assume também a responsabilidade pela formação e aperfeiçoamento de todo seu efetivo, incluindo-se os especialistas na nascente Engenharia Aeronáutica, curso já ministrado desde $1939^{2}$ na Escola Técnica do Exército - EsTE (órgão atualmente denominado Instituto Militar de Engenharia - IME, subordinado ao Comando do Exército).

Atualmente, o Instituto Tecnológico de Aeronáutica está vinculado ao Departamento de Ciência e Tecnologia Aeroespacial (DCTA), juntamente com o Centro Tecnológico Aeroespacial (CTA), na estrutura atual do Comando da Aeronáutica.

\subsection{A gênese do ITA no sonho de Casimiro Montenegro Filho}

Casimiro Montenegro Filho, nascido em 1904, foi um oficial das Forças Armadas, tendo se formado Tenente da Arma de Aviação do Exército Brasileiro em 1930. Diplomouse em Engenharia Militar pela Escola Técnica do Exército - EsTE (atualmente Instituto Militar de Engenharia - IME), em 1941, e participou efetivamente da criação e fortalecimento do Correio Aéreo Nacional (CAN), na década de 1930. Recebeu o título de Doutor honoris causa em duas instituições de ensino brasileiras. Faleceu aos 95 anos de idade, tendo alcançado a patente de Marechal-do-Ar, a mais alta da Aeronáutica, força a qual passou a pertencer, após a criação do Ministério, em 1941. Recebeu as honrarias de patrono da Engenharia Aeronáutica e do Instituto Histórico-Cultural da Aeronáutica (CAMBESES JÚNIOR, s/d.).

No entanto, seu sucesso vai muito além de títulos e honrarias militares. O projeto da vida do Marechal Montenegro que garante ainda hoje a perpetuação de seu sonho é o Centro Tecnológico Aeroespacial e, particularmente, o Instituto de Tecnologia de Aeronáutica.

Nos idos de 1940, com a recém-criada Força Aérea Brasileira, e a necessidade de desenvolvimento tecnológico para a construção de aeronaves e o treinamento de pilotos, vários dos seus comandantes percebiam a necessidade premente da criação de um centro que possibilitasse ao Brasil equiparação a outras nações em que tal domínio já era estabelecido.

Em 1945, o Coronel Aviador Casimiro Montenegro Filho, subchefe da Diretoria de Material da Força Aérea, ao viajar para os Estados Unidos recebeu a missão de acompanhar o recebimento de um lote de aviões e trazê-lo para o Brasil.

Como acumulava também a função de chefia na Subdiretoria de Técnica Aeronáutica, incluiu no roteiro uma vista à Wright Patterson Air Force Base, também

\footnotetext{
${ }^{1}$ Decreto-lei no 2.961.

${ }^{2}$ Decreto-lei no 1.735
}

RBHM, Vol. 16, n³1, p. 21-49, 2016 
denominada Wright Field: um centro que foi iniciado como campo de treinamento de pilotos militares e tornou-se um complexo de laboratórios com ênfase na pesquisa de construção aeronáutica.

O entusiasmo causado por esta visita levou o Coronel Montenegro a estender um pouco mais sua permanência em solo norte-americano e conhecer outra instituição que já lhe havia sido sugerida por um de seus assistentes, o engenheiro civil Arthur Soares Amorim e corroborada pelo Major Aviador Oswaldo Nascimento Leal: o Massachusetts Institute of Technology (MIT).

Argumentando a necessidade de maiores pesquisas, a equipe do Coronel Montenegro obteve, de seus superiores, a autorização para permanecer cerca de dois meses além do tempo previsto para aquela missão. $\mathrm{O}$ resultado de tais visitas foi o surgimento de uma obsessão na elaboração de um projeto e no processo de angariar apoiadores para a criação de um centro de pesquisa e formação de pessoal na área de Engenharia Aeronáutica.

\section{Massachusetts Institute of Technology: o espírito e o modelo}

Para melhor compreender o modelo do MIT e sua influência na formatação dos cursos pioneiros do ITA, faz-se necessária a verificação do "espírito" desta instituição norte-americana. "Espírito", neste caso, aproxima-se, semanticamente do termo componente de "esprit de corps", conceito tão caro às forças armadas que ressalta o sentimento de responsabilidade, honra, solidariedade e devoção a uma causa. Também estabelece certa conexão com o termo hegeliano zeitgeist, pois reflete a efervescência do pensamento científico da segunda metade do século XIX.

Este espírito do MIT tem raízes nas primeiras escolas europeias de ensino tecnológico e na necessidade de estabelecer um ensino adequado para o exercício das atividades relacionadas à engenharia, área que sofria constantes modificações, no decorrer de novos desenvolvimentos das ciências naturais.

\section{As origens europeias do ensino tecnológico}

Stratton e Mannix (2005, p. 6) mencionam que o início das escolas técnicas deve ser buscado na França, onde já havia, nos idos do séc. XIII, um destacamento do exército cujos membros eram denominados ingénieurs, título derivado do termo engenhos (dispositivos de guerra para cercos e fortificações). Posteriormente, surge a necessidade de diferenciar esses militares, pertencentes ao corps du génie daqueles profissionais que desempenhavam o ofício de projetar e supervisionar as construções de pontes, edifícios e vias públicas.

Os então denominados engenheiros civis recebiam instruções no Corps dês Pontset Chausées, fundada em 1747, mas oficializada em 1775, sob a liderança de JeanRodolphe Perronet (1708-1794) que definiu um programa de ensino que favorecia o vínculo estrito do currículo teórico com as oficinas, em que se estimulava a prática, com a tutoria dos alunos mais avançados.

Outro marco na história das instituições de ensino tecnológico da França e, por consequência da Europa, foi a École des Travaux Publics, fundada em 1794, cujo título foi 
alterado, no ano posterior, para École Polytechinique, destinada a prover, aos que conseguissem ser aprovados em um exame de seleção rigoroso, a formação científica básica necessária para qualquer engenheiro, através de um currículo de dois anos de estudos que contemplava Matemática, Física e Química. O egresso deveria buscar em outra instituição o aprendizado específico na área escolhida: civil, mecânica ou minas. (STRATTON; MANNIX, 2005, p. 7)

No início do século XIX, na cidade de Karlsruhe, Alemanha, Karl Friedrich Nebenius (1784-1857) fundou uma escola ${ }^{3}$, baseada nos moldes da politécnica francesa, porém com algumas características próprias: dois anos iniciais (correspondentes ao atual ensino secundário), com especial atenção à Matemática em detrimento de cadeiras como o Latim e Grego, comuns nas instituições clássicas; dois anos intermediários com estudos de ciências e aperfeiçoamento dos conteúdos matemáticos e, finalmente, dois ou três anos voltados para uma das áreas da engenharia disponíveis (construção, arquitetura, silvicultura, mecânica ou química).

O modelo de Karlsruhe deu origem a várias outras escolas na Alemanha, Áustria e Suiça, que posteriormente seriam elevadas à categoria de Technische Hochschulen, ou seja, centros de ensino tecnológico de nível avançado, com a garantia de equivalência dos graus nelas obtidos com aqueles das Universidades (STRATTON; MANNIX, 2005, p. 11).

\section{Antecedentes em solo norte-americano}

O cenário da economia norte-americana nos cinquenta anos entre 1820 e 1870 sofreu mudanças que o tornaram bastante distinto, em função das atividades que passam a ter maior relevância, como mostra Kerr:

"The percentage of people engaged in agriculture dropped from 83 to less than 48, while the percentage of those engaged in manufacturing, trades, and transportation increased from 17 to more than 31. In addition, a new class, called the personal service group, grew to embrace 18 per cent of the workers, and the professional group expanded from an almost negligible number to 3 per cent. The advent of the steam engine, the railroad, and the reaper, produced further shifts in occupations. The number of patents per year increased from only about 200 to 13,000." (KERR, 1931, p. 9)

A industrialização e o desenvolvimento dos inventos não tardaram em fomentar a criação de agrupamentos de pessoas interessadas na divulgação da ciência e no estabelecimento de um sistema educacional que pudesse acompanhar o progresso do ambiente industrial.

\footnotetext{
${ }^{3}$ Desde 2006 denominada Karlsruher Institut für Technologie (KIT), após a junção com o Forschungszentrum Karlsruhe, um centro de pesquisa em energia nuclear.
}

RBHM, Vol. 16, n³1, p. 21-49, 2016 
Neste período, especificamente em 02 de julho de 1862, foi promulgada a legislação que ficou conhecida como Morrill Act ${ }^{4}$. Esta determinação do poder legislativo concedeu a cada estado congregado 30.000 acres $\left(120 \mathrm{~km}^{2}\right)$ de terras federais, por membro da assembleia, para que fossem criadas, nesses locais, instituições de ensino que atendessem a uma necessidade latente da sociedade, especialmente do setor industrial. Também poderiam ser utilizados, neste intento, os recursos obtidos da venda de parte desse território.

As escolas, posteriormente conhecidas com Land-Grant Instituitions ${ }^{5}$, deveriam, de acordo com o texto legal:

"without excluding other scientific and classical studies and including military tactic, to teach such branches of learning as are related to agriculture and the mechanic arts, in such manner as the legislatures of the States may respectively prescribe, in order to promote the liberal and practical education of the industrial classes in the several pursuits and professions in life. "(Estados Unidos da América, 1862)

O resultado do Morrill Act foi sentido imediatamente em todo o território, já que, nos anos seguintes à sua assinatura, 37 estados valeram-se dessa subvenção. $O$ total de escolas de engenharia existentes nos Estados Unidos cresceu de quatro para dezessete, no ano de 1870 e setenta, em 1872 (KERR et al., 1931, p. 11).

Eram estas as condições que levaram à criação do MIT: no aspecto social, uma população com anseios democráticos de igualdade, cada vez menos cética e mais interessada pelas novidades científicas que os inventores e intelectuais tanto nativos quanto europeus desenvolviam; no aspecto econômico, uma migração da mão de obra e dos investimentos da agricultura (que passava a se mecanizar) para a indústria e serviços; e, no aspecto político, o apoio legal às mudanças de uma educação que não se percebia adequada para as necessidades das novas profissões.

Ampliação de mentes e sua iluminação através da Matemática e outras ciências, embebido de pioneirismo e com a preocupação clara a respeito de pesquisa e aplicações práticas: tal é o espírito das escolas de ensino tecnológico criadas neste período da História norte-americana, tal é o espírito do MIT, que adota os moldes das escolas politécnicas europeias (especialmente a alemã) e acrescenta o caráter empreendedor de indivíduos que vivenciaram a experiência de criar a escola que idealizaram.

\section{A Engenharia Aeronáutica do MIT}

Particularmente a respeito do curso de graduação em Engenharia Aeronáutica do MIT, que foi o modelo escolhido para o delineamento dos projetos que culminaram na criação do ITA, seus primórdios estão em 1896, com a construção de um primeiro túnel de

\footnotetext{
${ }^{4}$ Justin Smith Morril (1810-1898) que nomeia este ato jurídico foi senador americano pelo estado de Vermont.

${ }^{5}$ Contabilizadas até 2014, há 106 Instituições que são fruto do Morril Act original e de suas extensões, em 1890 e 1994.
} 
vento relacionado à tese do engenheiro Albert J. Wells e, um pouco mais tarde, em 1913, com a contratação de Jerome C. Hunsaker para oferecer o primeiro curso formalmente destinado à Aeronáutica (MIT, 1997).

A origem do curso de Engenharia Aeronáutica do MIT é registrada no Boletim v. 49 , n. 2. Este documento traz, na página 16, o relato do presidente Richard Maclaurin comunicando que o Engenheiro Jerome C. Hunsaker, Engenheiro naval formado pelo próprio MIT, após regressar de viagens em que visitou indústrias aeronáuticas da Inglaterra, França e Alemanha, se dedicaria a coordenar a criação de um laboratório capaz de instruir os futuros engenheiros de aeronáutica.

Hunsaker já havia demonstrado interesse pela pesquisa aeronáutica, durante sua graduação e, quando recebeu a missão de estabelecer o primeiro curso de Aeronáutica do MIT, construiu, em 1914, com seu assistente Donald Douglas, um túnel de vento ${ }^{6}$ (importante ambiente laboratorial de aerodinâmica).

A partir de 1914, já houve o registro de disciplinas isoladas tratando de assuntos relacionados com a Aeronáutica, oferecidos para os estudantes interessados, oriundos de diversos outros cursos do Instituto. $\mathrm{O}$ ingresso da primeira turma regular ocorreu no ano de 1926.

\section{O plano Smith}

Resgatando a empretira do Coronel Montenegro, após aproximadamente dezoito meses de planejamentos e redação do projeto, viajou novamente a Boston com o objetivo de entregá-lo ao professor Richard Harbert Smith (1894-?), chefe do Departamento de Engenharia Aeronáutica do MIT. Ao receber tal documento, o professor Smith manifestou seu desejo de viajar para o Rio de Janeiro e auxiliar na tarefa de montar o "MIT brasileiro".

Montenegro obteve, em seguida, a autorização do então Ministro da Aeronáutica, Joaquim Pedro Salgado Filho, para a contratação do professor Smith em regime temporário de seis meses, no ano de 1945, para o aperfeiçoamento do projeto de criação da escola.

Durante esse período, o professor Smith realizou diversas visitas a instituições de ensino de nível secundário e superior, culminando com um extenso trabalho, que ficou conhecido mais tarde como o "Plano Smith" apresentando:

- uma análise detalhada da situação da indústria e da pesquisa aeronáutica mundial nas primeiras décadas do século XX;

- uma lista de requisitos para uma bem sucedida instituição que se ocupasse de tal ramo científico e tecnológico; e

- diretrizes sobre as estruturas acadêmica e administrativa do proposto Instituto.

O ITA foi imaginado, desde o início, como parte integrante de um complexo de ensino e pesquisa: o Centro Técnico de Aeronáutica (CTA). Este conjunto de departamentos abrigaria laboratórios e ambientes de ensino, novamente tendo como molde o Instituto de Massachusetts.

O plano Smith apresentava algumas afirmações de difícil aceitação pelas instâncias superiores do Ministério da Aeronáutica, o que exigiu sempre a diligência do

${ }^{6}$ O primeiro túnel de vento do MIT havia sido construído em 1896 pelo estudante de engenharia Albert J. Wells.

RBHM, Vol. 16, n³1, p. 21-49, 2016 
coronel Montenegro. Um exemplo é a escolha do Reitor, que deveria ser feita por méritos e não por indicação ministerial. Conforme afirma o próprio professor Smith: "O reitor de uma escola como o ITA não poderá administrar pela autoridade e sim por consentimento." (SMITH, apud MORAIS, 2006, p. 119).

O parágrafo de abertura da parte inicial do plano Smith, denominada Recommendations for the CTA Law Foreward, tem um aspecto motivacional e inspirador quando afirma:

"Brazil will be the first major country of the world to integrate all educational and research facilities of a nation, in all fields which pertain to aeronautics the professional level, both civil and military, in one geographical center and in one legal organization. Not only will Brazil be the first nation to centralize these facilities but she will also be the first nation to plan these facilities, before they are created and started, as properly correlated components of a single organization."(SMITH, apud GARTENKRAUT, 2008, p. 214)

No decorrer do texto a ideia básica sempre reafirmada é a seguinte: o governo e a sociedade brasileira deveriam reconhecer a necessidade de desenvolver uma pesquisa e uma produção industrial aeronáutica suficiente para escapar da dependência dos países europeus e dos Estados Unidos, que haviam vivenciado um franco desenvolvimento, causado especialmente pelos conflitos bélicos em que se envolveram e que, ao término dos combates, procuravam descarregar seus equipamentos sobressalentes nos países que demonstrassem interesse em adquiri-los.

A segunda parte do Plano Smith, intitulada Basic policy and organic form of the CTA under the CTA Law, apresenta, detalhadamente, sua proposta de uma legislação completa que deveria ser construída para a criação do CTA, do qual o ITA era parte essencial. Esta minuta sugeria uma adaptação do modelo alemão de um centro de Aeronáutica, com orientações sobre a manutenção da vida administrativa, a captação e uso dos recursos e a estrutura acadêmica do Instituto de ensino e pesquisa.

O professor Smith, baseando-se nas bem sucedidas experiências das universidades norte-americanas, que eram de seu conhecimento, propôs um sistema de financiamento múltiplo governamental-privado, com ênfase na elevação do ensino, como elemento principal do desenvolvimento da Instituição como um todo, zelando pela garantia da independência da pesquisa e autonomia da gestão educacional.

$\mathrm{Na}$ continuação da referida seção, é apresentada uma característica inovadora em relação às demais instituições já existentes no país: a obrigatória assistência aos estudantes, fornecendo-lhes, além do ensino gratuito, moradia, alimentação, assistência médicaodontológica e amparo em viagens para a realização do exame de admissão e em visitas técnicas ao longo do curso.

Várias das sugestões do professor Smith foram acatadas pelo governo brasileiro, na redação dos diversos instrumentos legislativos que instituíram, aos poucos, o ITA e o CTA. Por exemplo, o Decreto $\mathrm{n}^{\circ} 27.695$, de 16 jan. 1950, já utiliza a nomenclatura Curso Fundamental e Curso Profissional, para descrever a estrutura da formação dos engenheiros 
no ITA; a portaria $\mathrm{n}^{\circ} 176$, de 02 set. 1948 , reforçada pela port. $\mathrm{N}^{\circ} 322$, de 15 dez. 1950 garante ao próprio Ministério da Aeronáutica a certificação dos diplomas emitidos pelo ITA.

\section{O ITA em suas primeiras décadas $(1950$ - 1970)}

\section{Os cursos de graduação}

No documento intitulado Informações sôbre o ano letivo de 1951, encontram-se as diretrizes gerais sobre a Instituição, os cursos, o regime escolar (normas acadêmicas, administrativas e disciplinares), bem como as regras para o ingresso.

A inscrição de um candidato no concurso de admissão tinha bastante semelhança com as diretrizes das Universidades brasileiras, regidas pelo Decreto 19.851, de 11 abr. 1931, que determinava a exigência da conclusão do curso científico ou clássico (correspondendo ao atual ensino médio), idoneidade moral. O ingresso no ITA possuía, porém, algumas características próprias: a exigência de uma ficha de sanidade e capacidade física, assinada por um médico e uma declaração, atestada, do estado civil solteiro.

Não havia a necessidade do pagamento de nenhuma taxa para a inscrição, por obediência ao Decreto-Lei $\mathrm{n}^{\circ}$ 8.816, de 24 jan. de 1946, que, no seu Art. $1^{\circ}$ determina que "ficam isentos do impôsto do sêlo os requerimentos e demais papéis apresentados para inscrição em exames ou provas, em estabelecimentos de ensino oficiais ou oficializados." (BRASIL, 1946).

A Comissão de Admissão, designada pelo reitor era composta, em 1950, pelos professores Murnaghan, Borzani, Phillips, Pompeia, Stokes e pelo Major Leal. Este grupo foi incumbido de definir os temas e bibliografia das questões pelas quais seriam avaliados os candidatos. A respeito dos temas de Matemática, a lista indicava conteúdos de Álgebra, Trigonometria, Sistemas lineares e Matrizes, Limites, Séries, Números complexos e Geometria Analítica,

Àqueles que fossem selecionados estavam garantidos moradia, alimentação, assistência médica e odontológica gratuitas, além de um auxílio de $\operatorname{Cr} \$ 200,00^{7}$ mensais durante seus cinco anos de estudo. Além disso, era facultado ao aluno do ITA escolher seguir a carreira militar, recebendo a patente de Tenente engenheiro, após se submeter ao treinamento militar adequado para o referido posto.

\section{O curso de pós-graduação em Matemática}

A importância de não limitar a atuação do Instituto somente nos cursos de graduação em áreas da Engenharia, mas de também favorecer pesquisas e o desenvolvimento acadêmico nas diversas ciências que pudessem se relacionar com a Aeronáutica é manifesta na legislação ${ }^{8}$ que dispõe sobre o ensino superior no Instituto Tecnológico de Aeronáutica, porém, mesmo antes de sua publicação, nas $9^{\mathrm{a}}$, $14^{\mathrm{a}}$ e $16^{\mathrm{a}}$

\footnotetext{
${ }^{7}$ Equivalente a cerca de $50 \%$ do salário mínimo da época.

${ }^{8}$ Lei no 2.165 , de 5 de janeiro de 1954.
}

RBHM, Vol. 16, n³1, p. 21-49, 2016 
reuniões da Congregação do ITA, ocorridas, respectivamente, em 06 set. de 1951, 05 maio 1952 e 26 jun. 1952, já foi assinalado o anseio do corpo docente do ITA pelo estabelecimento de cursos de pós-graduação.

Pouco tempo depois, em 30 de abril de 1954, quando da realização da $2^{\mathrm{a}}$ sessão da $31^{a}$ reunião da Congregação, a Comissão estabelecida apresentou suas considerações sobre o tema em voga, apresentando propostas, indicando que seria irreversível a decisão favorável a respeito do oferecimento dos cursos mais avançados; restava, apenas, serem determinados os detalhes da forma como isso seria realizado. Após as discussões, foi aprovada uma moção para permitir ao ITA conceder títulos de Doutor. Essa ação visava, em parte, o aperfeiçoamento acadêmico do próprio efetivo local, mas também indicava o interesse em aproveitar o Instituto, além de sua função intrínseca de formar engenheiros para a área de Aeronáutica, para proporcionar um ambiente de estudos mais avançados.

Cerca de dois anos depois, o primeiro Departamento do ITA a se valer da Regulamentação aprovada foi o de Matemática, que submeteu à apreciação da Congregação documento solicitando a criação do campo de Doutoramento em Matemática do ITA.

Uma das regras estabelecidas exigia do Departamento proponente que garantisse "os professores capacitados para orientar os trabalhos, a disponibilidade de meios e as condições iniciais a serem preenchidas por todos os candidatos" (ITA, 1956). A proposta listava, então, como professores capacitados, os doutores Francis Dominic Murnaghan, Nelson Onuchic, Flávio Botelho Reis e Kuo Tsai Chen, cuja vinda para o Instituto estava prevista para ocorrer dentro de algumas semanas da data de apresentação do pedido.

A respeito das condições específicas a serem atendidas pelos candidatos, o Departamento não quis criar um plano muito restritivo, preferindo analisar cada caso isoladamente, respeitando, no entanto, uma estrutura básica a ser cumprida, constando de:

"um exame preliminar para verificação de seus conhecimentos básicos e específicos em matemática, e em um assunto, referido com secundário, de outro setor técnico ou científico.

O candidato será submetido a um exame departamental escrito, cobrindo programas organizados pela comissão de doutoramento sobre dois grupos de assuntos:

assuntos gerais

assuntos especializados a serem determinados para cada candidato. exame escrito sobre assunto da tese e assunto correlato."(ITA, 1958)

A solicitação do Departamento de Matemática tinha a finalidade de aproveitar a possibilidade aberta pelas normas aprovadas em 1956 para que o então Auxiliar de Ensino Carlos Alberto de Buarque Borges pudesse obter seu título de Doutor em Ciências. Para ele foi estipulado o seguinte programa de estudos: Álgebra, Topologia dos Espaços Métricos, Análise Tensorial e Integração, Equações Integrais, Problemas de Valor de Contorno e Cálculo de Variações, Equações Diferenciais e o assunto da tese. 
A evolução natural foi o surgimento formaldo programa de pós-graduação no ITA, a partir de uma norma aprovada pela Congregação do Instituto, estabelecendo as diretrizes de um programa de estudos e pesquisa que culminasse no oferecimento do título de Mestre em Ciências, nos Departamentos de Ciências, Engenharia, Direito, Economia ou Humanidades do Instituto.

A Comissão que ficara responsável pelos estudos e preparação da proposta foi presidida pelo professor Nello da Silva Allan, contando com a contribuição, entre outros, do professor José Thomaz Senise e do professor Paulo Ernesto Tolle.

A proposta dos membros para a estrutura do programa corresponde àquela que até hoje é convencional nas Instituições de Ensino Superior, ou seja, estudos avançados, a produção de uma pesquisa sob a supervisão de um professor orientador e posterior defesa perante uma banca examinadora.

$\mathrm{Na}$ norma então apresentada, havia quinze itens, sendo alguns aqui destacados em caráter de exemplo:

"2 - O ITA concederá o título de Mestre em Ciências, com a especificação “obtido no Departamento de ...” incluída no diploma, a candidatos que completarem um programa constando de: um currículo aprovado de matérias, uma tese aceitável e outros requisitos estabelecidos por estas normas, pelos departamentos interessados e pela Comissão de Pós-Graduação.

[...]

9 - Para admissão aos programas de pós-graduação, o candidato deverá ser portador de diploma do curso superior e mais:

Para escolher como principal um departamento do grupo de Ciências ou Engenharia: ter conhecimentos de matemática e física equivalentes nos três primeiros anos do ITA, na especialidade do departamento.

[...]

12 - Após a aprovação nas matérias do currículo e término dos trabalhos de teses, o estagiário deverá:

$1^{o}$. Obter a aprovação do esboço da tese pelo orientador.

$2^{\circ}$. Fazer a apresentação pública de seu trabalho, perante banca nomeada pela Comissão de Pós-Graduação. ”(ITA, 1961)

Posteriormente, com o aproveitamento das experiências desenvolvida a partir de 1961, foi expedida, em 1968, a regulamentação do programa, com as normas dos cursos de Mestrado e Doutorado, bem como da Seção de Pós-Graduação, destinada a zelar por tais cursos.

A portaria interministerial $n^{\circ}$ 18/GM3, de 20 de fevereiro de 1968, assinada pelo então Ministro da Aeronáutica, Márcio de Souza e Mello, determina que as "normas gerais de funcionamento do Curso de Pós-Graduação serão, de ora em diante, fixadas pelo Diretor Geral do CTA, por proposta da Congregação do ITA”. 
Apoiada pelas atividades então desempenhadas pela Comissão de pós-graduação, estas "Normas Gerais" trazem alguns aspectos destacados a seguir, tratando do ingresso de estudantes, o currículo, o aproveitamento, e a pesquisa (com a orientação e a defesa).

"Art. 60 - Para admissão nos curso de Pós-graduação, o candidato deverá ser portador de diploma de curso superior e satisfazer outras exigências do Curso e, quando fôr o caso, do departamento interessado.

[...]

Art. 22 - Todo aluno do Curso de Pós-Graduação, terá, desde o início de seu programa, um professor Orientador Acadêmico, designado pelo Chefe do Curso de Pós-Graduação que o orientará na escolha de matérias e nos demais aspectos acadêmicos do programa de estudos.

[...]

Art. 26 - o ITA concederá o título de Mestre em Ciências aos candidatos que completarem um programa constando de:

Um mínimo de 30 créditos, de acordo com o Programa de Estudos aprovado conforme o artigo 25 destas Normas;

Uma tese com alguns elementos de originalidade, à qual serão atribuídos nove dos trinta créditos acima referidos;

Uma média, no mínimo igual a 7,5, computada de acôrdo com o art. 15 destas Normas.

[...]

Art. 29 - A apresentação final da tese será feita em público, perante comissão nomeada pelo Curso de Pós-Graduação, e constituída de, pelo menos, cinco membros, dentro os quais o orientador da tese, um membro da Comissão de Pós-Graduação e um membro convidado, não pertencente aos quadros do ITA.” (ITA, 1968)

Quase simultaneamente ao início das atividades de pós-graduação no ITA, ocorreu um fervilhar de ações similares em instituições, como o Instituto Nacional de Matemática Pura e Aplicada (IMPA), criado em 1952, e a Universidade de Brasília (UnB), criada em 1961.

A Lei no 4024, de 20 dez. 1961, a primeira a ostentar o título de Lei de Diretrizes e Bases da Educação Nacional, substituída duas vezes, em 1971 e em 1996, estabelecia, sem esclarecer com maiores detalhes, em seu art. 69, que "nos estabelecimentos de ensino superior podem ser ministrados os seguintes cursos: [...] b) de pós-graduação, abertos a matrícula de candidatos que hajam concluído o curso de graduação e obtido o respectivo diploma;" (BRASIL, 1961)

Estas ações fizeram com que, no ano de 1965, o Ministro da Educação e Cultura Flávio Suplicy de Lacerda expedisse ao Conselho Federal de Educação - CFE (este órgão teve sua denominação alterada para Conselho Nacional de Educação a partir de 1995) uma solicitação de esclarecimentos sobre tal matéria, pois, segundo o próprio Ministro, não poderia deixar de ser considerada "a necessidade de implantar e desenvolver o regime de cursos-pós-graduação em nosso ensino superior” e, apesar de alguns programas pioneiros já 
estarem em atividade, deveria ser observada "a imprecisão, que reina entre nós, sobre a natureza desses cursos" (CFE, 1965).

O CFE emitiu, em 13 dez. 1965, o parecer CFE 977/1965, em resposta à solicitação ministerial. Após discorrer sobre a origem histórica, reafirmar a necessidade, conceituar claramente e expor exemplos a respeito do tema "pós-graduação", os signatários do parecer $^{9}$, preocuparam-se em eleger um modelo adequado para o momento de nascimento e expansão das Instituições de ensino superior do Brasil e de crescimento industrial e econômico então vivenciado.

A estes legisladores coube a obrigação de "atendendo à solicitação do Sr. Ministro e, ao que determina o Estatuto do Magistério, definir e fixar as características dos cursos de Mestrado e Doutorado" (CFE, 1965). Tais características são apresentadas, na seção intitulada "Definição e Características do Mestrado e Doutorado", em que constam, entre outras, as seguintes normas:

"Em primeiro lugar, de acordo com a doutrina exposta nesse parecer, propomos o escalonamento da pós-graduação em dois níveis: mestrado e doutorado.

[...] O programa de estudo comportará duas fases. A primeira fase compreende principalmente a freqüência às aulas, seminários culminando com um exame geral que verifique o aproveitamento e a capacidade do candidato. No segundo período o aluno se dedicará mais à investigação de um tópico especial da matéria de opção, preparando a dissertação ou tese que exprimirá o resultado de suas pesquisas.

[...] A luz da doutrina aqui exposta sobre a natureza e processos da pós-graduação, podemos formular as seguintes conclusões sobre as características fundamentais dos cursos pós-graduados correspondentes aos dois níveis:

1) A pós-graduação de que trata a alínea b do art. 69 da Lei de Diretrizes e Bases é constituída pelo ciclo de cursos regulares em seguimento à graduação e que visam a desenvolver e aprofundar a formação adquirida nos cursos de graduação e conduzem à obtenção de grau acadêmico.

[...]

6) Os cursos de mestrado e doutorado devem ter a duração mínima de um e dois anos respectivamente. Além do preparo da dissertação ou tese, o candidato deverá estudar certo número de matérias relativas à sua área de concentração e ao domínio conexo, submeter-se a exames parciais e gerais, e provas que verifiquem a capacidade de leitura em línguas estrangeiras. Pelo menos uma para o mestrado e duas para o doutorado. [...]

\footnotetext{
${ }^{9}$ A. Almeida Júnior (presidente da C. E. Su), Newton Sucupira (relator), Clóvis Salgado, José Barreto Filho, Maurício Rocha e Silva, Durmeval Trigueiro, Alceu Amoroso Lima, Anísio Teixeira, Valnir Chagas e Rubens Maciel (membros).
}

RBHM, Vol. 16, n³1, p. 21-49, 2016 
9) Do candidato ao Mestrado exige-se dissertação, sobre a qual será examinado, em que revele domínio do tema escolhido e capacidade de sistematização; para o grau de Doutor requer-se defesa de tese que represente trabalho de pesquisa importando em real contribuição para o conhecimento do tema.

[...]

12) Para matrícula nos cursos de pós-graduação, além do diploma do curso de graduação exigido por lei, as instituições poderão estabelecer requisitos que assegurem rigorosa seleção intelectual dos candidatos. Se os cursos de graduação devem ser abertos ao maior número, por sua natureza, a pós-graduação há de ser restrita aos mais aptos."(CFE, 1965)

Há conformidade entre as diretrizes estabelecidas pelo ITA, tanto nas Normas de 1968 como nas de 1961, e o balizamento ditado pelo CFE. Tais semelhanças devem-se, prioritariamente, ao fato de que o modelo adotado como referência adequada pelos Conselheiros - o modelo norte-americano - já era o praticado pelo ITA, graças à formação

\section{Graduação em Matemática: o curso que quase aconteceu}

Em 26 de abril de 1962, durante a realização da $97^{a}$ reunião da Congregação do ITA foi apresentado o Memorando 015-IC/62, nomeando uma comissão ${ }^{10}$ para examinar e propor medidas tratando de uma sugestão do Magnífico Sr. Reitor, professor Marco Antônio Gugglielmo Cecchini, de criar cursos completos de Física, Química e Matemática.

No período de 18 abr. 1963 a 25 jun 1964, a Comissão teve suas atividades suspensas, de acordo com informação prestada pelo Professor Pompéia, após entendimento com a Reitoria.

Finalmente, na $160^{\mathrm{a}}$ reunião, em 29 out. 1964 foi apresentado um relato, novamente pelo professor Pompéia, explanando que o motivo da constituição da Comissão para estudar a criação de cursos de Física, Química e Matemática no ITA teria sido "a idéia de se estabelecerem cursos completos das matérias citadas em escolas de engenharias e entendendo que, desaparecido o apoio que a essa ideia dava o Ministério da Educação, a Comissão também deveria extinguir-se." (ITA, 1964).

Na mesma reunião o professor Leônidas informou que tinha conhecimento de haver interesse da administração municipal de São José dos Campos e do Conselho Estadual de Educação para a instalação de uma Faculdade de Filosofia, cujos cursos de ciências funcionariam em cooperação com o ITA.

${ }^{10}$ Os membros designados foram os professores Paulus Aulus Pompéia (Física), Padraic Cathal Dunne (Aeronaves), Luiz Valente Boffi, Francisco Antonio Lacaz Netto (Matemática), Arp Procópio de Carvalho (Humanidades), Cyro Marino e Odelar Leite Linhares (Computação), presididos pelo primeiro. 
Houve manifestações de apoio, sugerindo a reativação da Comissão, por considerar que, seria fácil para o ITA, com pequena adaptação, receber vinte ou trinta alunos anualmente para cursar Física ou Matemática.

No entanto, alertas foram feitos por outros professores que consideraram prematura a ideia de iniciar novos cursos sem ter estabilizado os trabalhos no setor de Engenharia. Em relação a essa ressalva, o professor José Thomaz Senise disse que a dedicação a novos cursos (citando, inclusive, os de pós-graduação que já estavam em funcionamento) é elemento que levaria à melhoria do padrão dos demais e razão para o reforço dos Departamentos.

O professor Cecchini, favorável ao retorno das atividades da Comissão, apontou que: “1) A lei criadora do ITA não o faz especificamente escola de engenharia, mas atribuilhe caráter mais geral; 2) as instituições americanas que serviram de modêlo para o ITA mantém cursos de ciências a par de cursos de engenharias." (ITA, 1964)

Através do Memorando 63-IC/64 houve constituição de nova Comissão ${ }^{11}$ para estudar o caso.

Não há, nas atas das reuniões posteriores da Congregação, nenhum outro comentário sobre este assunto. Conjecturamos que a turbulência política e social do ano em questão tenha demandado os esforços do corpo docente em outras comissões e ações, em prejuízo desta questão. Outra hipótese para a descontinuidade das atividades desta comissão é a mudança da reitoria, que passou do professor Marco Antônio Gugglielmo Cecchini (defensor da demanda) para o professor Luiz Cantanhede de Carvalho Almeida Filho.

\section{Matemáticos do ITA nas primeiras décadas}

O professor Richard Harbert Smith, além de ter sido o autor do plano que lançou as bases da fundação do CTA (e do ITA, por consequência), também ocupou a cadeira de Reitor do Instituto em seus anos iniciais (1946 a 1951). A experiência do professor Smith estendia-se do aspecto científico para a prática administrativa, pois em seu currículo constavam a formação como engenheiro no MIT, a participação na Segunda Grande Guerra, num grupamento de aviação da Marinha norte-americana, a obtenção do título de Ph.D. na Universidade Johns Hopkins, a realização de pesquisas no Instituto de Aerodinâmica de Göttingen e o exercício como docente e chefe de departamento de Engenharia Aeronáutica do MIT entre 1929 e 1945.

A permanência do professor Smith no ITA após sua criação foi bem aproveitada pelo Coronel Montenegro para a constituição das estruturas básicas do Instituto, em especial para a formação do corpo Docente e definição de algumas questões acadêmicas.

Várias contratações de professores de alto nível em suas áreas foram possíveis graças aos convites feitos pelo professor Smith, figura de grande prestígio nos Estados Unidos. (MONTENEGRO FILHO, 2006, p. 16)

\footnotetext{
${ }^{11}$ Presidida pelo professor José Thomaz Senise (Eletrotécnica) e constando também com os professores Mário Alves Guimarães (Física), Gustave Rabson (Matemática), Wolfgang Ferdinand Valter (Química) e Fernando Venâncio Filho (Estruturas).
}

RBHM, Vol. 16, n³1, p. 21-49, 2016 
Outros fatores que influenciaram a vinda destes expoentes estrangeiros foram o salário e facilidades oferecidos. Todos os professores contratados tinham direito a uma residência nas dependências do CTA e faziam jus a um salário mensal de cerca de US\$ $1.000,00$ da época, bem acima do salário médio de instituições do país de origem da maioria dos contratados. Por exemplo, a Universidade John Hopkins pagava a seus professores, no ano de 1950, cerca de US\$ 8.000,00 por ano (CASSUTO, 2011).

O professor Smith desejava trazer professores estrangeiros também para o denominado Curso Básico, isto é, os dois anos iniciais dos cursos em que deveriam ser apresentados os conteúdos básicos de Matemática, Física e Química. Nesse quesito, o Coronel Montenegro interferiu, afirmando que havia, aqui no Brasil, profissionais à altura desta demanda e sugeriu que o primeiro reitor visitasse a Universidade de São Paulo para ter com o professor Gleb Wataghin ${ }^{12}$.

Após este contato, surgiu o nome do professor Paulus Aulus Pompéia, um dos brilhantes pupilos de Wataghin, formado em Física pela Faculdade de Filosofia Ciências e Letras (USP), com experiência na pesquisa de detecção de raios cósmicos e com participação no desenvolvimento de um sonar, utilizado pela Marinha brasileira no período da Segunda Guerra.

Além do professor Pompéia, os primeiros professores brasileiros convidados para constituírem o corpo docente foram Fernando Pessoa Rebello, Jacek Piotr Gorecki, Paulo Ernesto Tolle, Octávio Gaspar de Souza Ricardo, Jeremias Chrispim e Álvaro Miguez Bastos da Silva.

Também foi membro importante nestes anos iniciais, o professor Ernesto Luiz de Oliveira Junior, que já havia sido assistente do professor Fantappiè e trabalhou com o professor Smith agindo como interlocutor com as demais instituições e divulgando o modelo de ensino do ITA.

Especificamente na área da Matemática, considerando especialmente a escassez de mão de obra qualificada para o ensino consoante com a visão modernizadora que seus cursos deveriam imprimir, houve a necessidade de importação de professores qualificados para assumir tal empreita.

A seguir são listados os professores ${ }^{13}$ do Departamento de Matemática, vinculados à Divisão Fundamental do ITA (posteriormente houve a separação em Divisões de Matemática, Física e Química), a partir de dados obtidos nos Catálogos de Curso das décadas de 1951 a 1968.

Desses membros do corpo docente do ITA, alguns também atuaram com destaque em outras instituições de ensino brasileiras, como os professores Nelson Onuchic (UNESP) e Leônidas Hegenberg (PUC-SP).

12Gleb Vassilievich Wataghin (1899-1986) veio para a USP a convite de Teodoro Ramos por indicação de Enrico Fermi e orientou, entre outros, César Lattes, Oscar Sala, Mário Schenberg e Marcello Damy de Souza Santos.

${ }^{13}$ Havia quatro classificações profissionais do corpo docente:Professores (por vezes identificados com a terminologia em inglês Full Professors), Professores Associados, Professores Assistentes e Auxiliares de ensino. Em algumas situações, foram contratados também Técnicos de nível médio para dar suporte às atividades do Departamento. 
Outros desses profissionais, com dedicação profissional quase exclusiva ao ITA, tiveram sua evolução profissional e acadêmica registradas nos documentos do Instituto, como é o caso dos professores Leo Huet Amaral e Toshio Hattori.

Docentes de Matemática do ITA entre 1951 e 1968.

\begin{tabular}{|c|c|c|}
\hline Professores (FullProfessors) & $\begin{array}{l}\text { Professores Associados/ } \\
\text { Professores Assistentes }\end{array}$ & Auxiliares de Ensino \\
\hline $\begin{array}{l}\text { Francis Dominic Murnaghan } \\
\text { Francisco Antonio Lacaz Netto } \\
\text { Ernesto Luiz de Oliveira Jr. } \\
\text { Leonidas H. B. Hegenberg } \\
\text { Flávio Botelho Reis } \\
\text { Leo Huet Amaral } \\
\text { Nelson Onuchic } \\
\text { Kuo Tsai Chen } \\
\text { Gustav Rabsen }\end{array}$ & $\begin{array}{l}\text { Carlos Alberto Buarque Borges } \\
\text { Viktor A. Vyssotsky } \\
\text { Rubens Gouvea Lintz } \\
\text { Rubens Monteiro Lamparelli }\end{array}$ & $\begin{array}{l}\text { Artibano Micali } \\
\text { Carlos Alberto de Buarque Borges } \\
\text { Geraldo S. S. Ávila } \\
\text { Mario Pereira Orsini } \\
\text { Nello da Silva Alan } \\
\text { Rodolfo G. Pedreira } \\
\text { Rubens Monteiro Lamparelli } \\
\text { Silvio Machado } \\
\text { Juarez Milano } \\
\text { Neriglissor Cavalcanti } \\
\text { Salvador Saad } \\
\text { Toshio Hattori } \\
\text { Agildo de Almeida } \\
\text { Albrecht Gerhardt Huppmann } \\
\text { Sebastião Medeiros da Silva } \\
\text { Natalino Adelmo Molfetta } \\
\text { Rodolfo Vilhena de Moraes } \\
\text { Antônio Washington A. de Souza } \\
\text { Djalma Galvão Carneiro Pessoa } \\
\text { José CleobaldoChianca } \\
\text { Tamio Shimizu }\end{array}$ \\
\hline
\end{tabular}

Fonte: ITA - Catálogos de cursos de Engenharia 1951 a 1968.

Serão apresentadas a seguir informações e características de alguns dos professores previamente mencionados, estabelecendo três conjuntos:

i) os estrangeiros;

ii) primeira geração de brasileiros; e

iii) segunda geração de brasileiros.

Pertencem ao primeiro grupo os professores Francis DominicMurnaghan, Chen To Tai e KuoTsai Chen. Estes, ao aceitar o convite para constituir o núcleo de estruturação do ITA, deixaram marcas na Matemática ensinada no Instituto e nos cursos estabelecidos.

A primeira geração nacional é definida pelos professores Francisco Antônio Lacaz Netto, Leônidas Helmuth Baebler Hegenberg, Flávio Botelho Reis, Leo Huet Amaral, Carlos Alberto de Buarque Borges e Nelson Onuchic. A segunda geração contempla, entre outros, os professores Toshio Hattori, Luís Carlos Rossato e Walter Winkel.

A primeira geração, por sua convivência com os professores estrangeiros, recebeu destes formação científica e operacional para o ensino das disciplinas nos cursos. 
Os professores constituintes da segunda geração ingressam no ITA num período em que são iniciados e reforçados vínculos entre organizações científicas voltadas para a Matemática, como o Instituto de Matemática Pura e Aplicada (IMPA) e a Sociedade Brasileira de Matemática (SBM). Vários destes profissionais que ainda não possuíam título de doutor receberam o apoio do ITA para cursarem programas em universidades americanas para seu aperfeiçoamento.

\section{Francis DominicMurnaghan}

O matemático mais importante presente no início das atividades do ITA foi Francis Dominic Murnaghan. Nascido na Irlanda, em 1893, graduou-se na University College Dublin (UCD), em 1913; após mudar-se para os Estados Unidos, estudou na Johns Hopkins University, em Baltimore, Maryland, tendo obtido o título de Ph.D. em 1916. (LEWIS, 2003, p. 101)

A importância do professor Murnaghan é ressaltada por D’Ambrosio (2011, p. 86) quando afirma que "Murnaghan imprimiu características muito originais à Matemática ensinada e pesquisada no ITA, o que contribuiu, em parte, para o grande desenvolvimento da indústria avançada no Brasil”".

Francisco Mendes de Oliveira Castro (1902-1993), então professor da Escola Nacional de Engenharia, prefaciando o livro Álgebra Linear e Trigonometria, de autoria do professor Murnaghan, menciona as honrarias por este já recebidas, quando afirma que, no reconhecimento de seus trabalhos originais de pesquisa matemática, "foi eleito membro da 'Royal IrishAcademy', da 'American Philosophical Society', da 'National Academy of Sciences', da 'Academia Nacional de Ciências Exactas de Lima' e da 'Academia Brasileira de Ciências"” (CASTRO, 1954 apud MURNAGHAN, 1954, p. 13).

São apontadas como qualidades de Murnaghan sua experiência de trabalho em diversos centros de excelência no ensino de engenharia e sua preocupação constante com as necessidades pedagógicas das cadeiras de Matemática e relembra as palavras do próprio Murnaghan (1954, p. 14) ao afirmar claramente que "o sucesso do ensino da Matemática depende muito da personalidade do professor e todo professor deveria ter tempo e oportunidade de desenvolver aspectos da Matemática que o seduzissem”.

Há um registro na ata da $90^{\mathrm{a}}$ reunião da Congregação do ITA, realizada em 27 de abril de 1961, em que, por ocasião do encerramento do contrato do professor Murnaghan e seu retorno para os Estados Unidos, foi lida e transcrita uma missiva de autoria do Professor Lacaz Netto, em sua homenagem:

“Em 1948, quando da criação do I.T.A. convidado pelo professor Richard Smith, assumiu a direção do Departamento de Matemática de nosso instituto o professor Francis D. Murnaghan. Há dias foi noticiado, oficialmente, o afastamento de nossa escola, do preclaro e ilustre matemático. Como seu antigo colaborador - o que maior contato manteve com ele, cabe-me a honra de, em nome do Departamento de Matemática, manifestar à Congregação nosso pesar pelo seu afastamento, e 
apresentar-lhe, ao professor Murnaghan, infelizmente nos Estados Unidos, nossos mais sinceros agradecimentos, por tudo que fez em benefício do departamento, da cultura matemática e do ensino no Brasil. Notável foi a influência do professor Murnaghan na formação do ITA, que muito lhe deve. Organizou ele o Departamento de Matemática, dando-lhe estrutura moderna, ainda não igualada por outra escola de engenharia do país; e em qualquer assunto que dizia respeito a nosso instituto, sua opinião sempre foi ouvida, e com certeza ainda será ouvida (se necessário), com o respeito e o acatamento que merece a palavra de um homem de bom senso, de caráter e de cultura. ”(ITA, 1961)

Sobre sua conduta na chefia do Departamento, fica nítido o zelo pelo corpo discente, a partir de normas internas estabelecidas para o melhor aproveitamento do conteúdo ensinado.

"Para o Departamento de Matemática fixou ele certo número de normas, das quais desejo destacar duas: a primeira, sobre a obrigatoriedade de um só professôr responsabilizar-se pela parte teórica do curso, como pela de exercícios também, obrigando, destarte, o professôr a manter mais contato com o aluno, sentindo suas falhas e aproveitamento; a segunda, a da não realização, para uma classe, de dois cursos de Matemática, simultaneamente, para que o aluno possa melhor dominar a matéria”.(ITA, 1961.)

Finalmente, o professor Lacaz Netto faz uma declaração sobre a importância do professor Murnaghan como um pilar do ensino de Matemática em cursos da área de tecnologia:

"A influência que o chefe do Departamento de Matemática do ITA, estava exercendo no ensino da Matemática aplicada no Brasil, só podia ser comparada com a dos primeiros professôres da Faculdade de Filosofia de São Paulo - Luigi Fantappie e Jacomo Albanese - na Matemática Pura. O tempo comprovará meu juízo. Aproveitando duas palavras muito do agrado do professor Murnaghan, termino minha oração com frase que poderá encimar os umbrais do ITA: 'Para honra e fama de nosso Instituto, aqui lecionou o professor Francis Murnaghan'.'(ITA, 1961.)

Após o profícuo período de permanência no Brasil, Murnaghan retornou para os Estados Unidos, prestando consultoria na área de Matemática aplicada para a Marinha norte-americana, em uma unidade de pesquisa e testes, sediada em Maryland. (LEWIS, 2003, p. 103)

KuoTsai-Chen

RBHM, Vol. 16, n³1, p. 21-49, 2016 
O matemático chinês KuoTsai-Chen nasceu em Chekiang, na China, em 1923. Graduou-se em 1946, pela Universidade Nacional Associada do Sudeste (西南联合大学), em Kungming, no ano de 1946.

Trabalhou por dois anos como professor Assistente na Universidade de Xangai, antes de ir para a Universidade de Indiana, nos EUA, para estudar com Samuel Eilenberg, tendo o acompanhado para a Universidade de Columbia, em Nova York, onde obteve seu doutorado defendendo a dissertação com o título Integration in FreeGroups, em 1950.

Após este período, lecionou nas universidades de Princeton e Illinois (EUA) e de Hong Kong (região, na época, sob controle britânico). Durante essas experiências profissionais, publicouos livros Integration in free groups (1951), Commutator calculus and link invariants (1952), Isotopy invariants of links (1952), e A group ring method for finitely generated groups (1954). (HAIN; TONDEUR, 1990).

Em 1958, o professor Chen iniciou suas atividades no ITA, primeiro como Professor Associado, tendo sido promovido a Professor Pleno em 1959. Foi o segundo chefe do Departamento de Matemática, sucedendo o professor Murnaghan.

Nos últimos anos em que esteve no ITA (1960-1962) o professor Chen foi convidado para realizar duas visitas no Instituto de Estudos Avançados de Princeton e, em seguida foi convidado para lecionar na Universidade de Rutgers, posição que ocupou a partir de 1963, até sua morte, em 1987, com um único hiato, entre 1964 e 1965, em que lecionou na Universidade Estadual de Nova York, em Buffalo.

De acordo com O'Connor e Robertson (2007), a produção matemática de Chen pode ser dividida em três períodos: seu estudo inicial sobre Teoria de Grupos e sua relação com hiperesferas; seu trabalho subsequente sobre o formalismo em Equações diferenciais e, após uma gradual evolução, sua obra mais importante, que ocupou seus últimos vinte anos de vida e pesquisas: integrações iteradas e teorias de homotopia.

\section{Chen To Tai}

Chen To Tai nasceu, em 1915, na cidade chinesa de Luzhi, graduou-se em Física, em 1937, na Universidade de Tsig-Hua e obteve seus títulos de mestre e doutor em Engenharia de Comunicação, pela Universidade de Harvard em 1943 e 1947, respectivamente.

Trabalhou na Universidade de Ohio de 1954 a 1956, quando foi convidado para auxiliar na criação da Divisão de Engenharia Eletrônica do ITA. Permaneceu no Instituto até 1961, retornando para a mesma instituição nos Estados Unidos. Em 1964 assumiu o cargo de professor na Universidade de Michigan em Ann Arbor, nela permanecendo até a obtenção do título de professor emérito, em 1986.

Em 1985, o professor Tai retornou ao Brasil para ministrar aulas no Instituto Nacional de Pesquisas Espaciais (INPE), instituição também sediada em São José dos Campos - SP, na função de professor visitante, subsidiado pelo programa Fulbright.

Apesar de sua formação inicial em física e seus estudos pós-graduados em Engenharia, o Professor Tai é uma referência em pesquisas em Matemática aplicada, especialmente na área de eletromagnetismo e antenas. (NATIONAL ACADEMY OF 
ENGINEERING, 2008, p. 306) Em 1971 publicou o livro “DyadicGreen'sFunctions in EletromagneticTheory" que popularizou o uso das funções de Green na solução de problemas relacionados a projetos de antenas.

Tendo a colaboração de John Harold Bryant (1920-1997), escreveu o artigo "New insights intoHertz'stheoryofeletromagnetism", em que mostra uma forma alternativa de obter as equações de Maxwell.

A dedicação do professor Chen To Tai ao ensino era tão notória e reconhecida pelos seus pares que, no ano 2000, foi instituído pela Institute of Electrical and Electronics Engineers (IEEE) Antennas and Propagation Society o Prêmio Chen-To Tai de Distinção Educacional para homenagear educadores de destaque na área de antenas e propagação. O primeiro agraciado foi o professor Ronald Wyeth Percival King (1905-2006), em 2001. O próprio professor Tai também foi homenageado pela IEEE com a Heinrich Hertz Medal, em 1998.

Nas homenagens póstumas publicadas por uma das comunidades científicas da qual o professor Tai era membro, sintetizam-se suas características marcantes:

Everyone who knew Chen-To Tai will remember him as a kind gentleman and scholar who made magnificent contributions to science and engineering and gave generously of himself. He was a dedicated teacher known for the clarity of his lectures and was loved and respected by his students and colleagues. Most important, he was a decent and compassionate human being.(NATIONAL ACADEMY OF ENGINEERING, 2008, p. 308.)

Francisco Antonio Lacaz Netto

Francisco Antonio Lacaz Netto nasceu na cidade de Guaratinguetá (SP) em 1911. Formou-se pela Escola de Odontologia e Farmácia de Itapetininga em 1929 e pela Escola Politécnica da USP em 1932, como farmacêutico e engenheiro.

Posteriormente, licenciou-se em Matemática pela Faculdade de Filosofia Ciências e Letras da USP, em 1935 e complementou seus estudos na Universidade de Roma, em 1939.

Depois de lecionar em diversas instituições, entre elas a Escola Politécnica da USP, a Faculdade de Engenharia Industrial da Pontifícia Universidade Católica de São Paulo e a Faculdade de Filosofia Ciências e Letras da Universidade Mackenzie, ingressou no ITA em 1950, como professor Associado do Departamento de Matemática. Foi reitor do ITA no período de 1966 a 1973.

Escreveu 25 livros e mais de uma centena de artigos e monografias sobre Matemática. Faleceu em 1991 e, neste mesmo ano, o Auditório do ITA, localizado próximo à Biblioteca, foi batizado em sua homenagem. Além disso, há, desde 1996, uma láurea para o aluno que realizar o melhor trabalho de graduação (TG, antigo Trabalho Individual - TI) que recebe também o seu nome. 
De acordo com Calabria (2012, p. 13) o professor Lacaz Netto, era "uma pessoa culta, intelectualizada e organizada", tendo realizado estudos e produções em Fundamentos da Matemática, Teoria dos Números e História da Matemática.

\section{Nelson Onuchic}

Informações bastante detalhadas sobre a vida acadêmica do professor Nelson Onuchic podem ser encontradas no trabalho de Badin (2006), do qual foi sintetizado este breve relato de suas contribuições, com ênfase no que tange ao ITA.

Licenciado em Física pela Faculdade de Filosofia, Ciências e Letras do Instituto Mackenzie (atual Universidade Mackenzie), foi convidado pelo Professor Francisco AntonioLacaz Netto, seu antigo professor de graduação, a assumir a vaga de Auxiliar de ensino, cargo ocupado de 1951 a 1955.

Contratado como Professor Assistente permaneceu ainda no ITA de 1956 a 1958.Durante este período, realizou estudos com o Professor Chaim Smuel Hönig, culminando com a produção de sua tese de doutorado intitulada Estruturas Uniformes sobre P-Espaços e Aplicações da Teoria destes Espaços em Topologia Geral, apresentada na Faculdade de Filosofia, Ciências e Letras da Universidade de São Paulo (USP) 1957.Participou do $1^{\circ}$ Colóquio Brasileiro de Matemática, na cidade de Poços de Caldas (MG).

Foi convidado pelo professor João Dias da Silveira para criar o Curso de Matemática da Faculdade de Filosofia, Ciências e Letras de Rio Claro (hoje Universidade Estadual Paulista, campus de Rio Claro).

Emparceria com Philip Hartman, escreveu o artigo On the Asymptotic Integration of Ordinary Differential Equations, publicado no Pacific Journal of Mathematics, em 1963.O principal resultado apresentando nesse trabalho ficou conhecido como Teorema de Hartman-Onuchic.

Neste mesmo ano, foi convidado para a posição de Professor Pleno de Matemática do ITA, pelo professor Lacaz, então Chefe do Departamento de Matemática. Por razões pessoais, o convite não foi aceito e, em 1966, o professor transferiu-se para o departamento de Matemática da Escola de Engenharia de São Carlos (EESC-USP). Nesta instituição, trabalhou arduamente no estabelecimento do programa e cursos de pósgraduação, especificamente nas áreas de Análise e Topologia, tendo participado da criação do Instituto de Ciências Matemáticas de São Carlos (ICMSC), em 1971.

Faleceu em 1999, deixando em sua descendência acadêmica, entre outros, Antonio Fernandes Izé, o primeiro Mestre em Ciências (Matemática) a obter o seu título no ITA, em 1965.

\section{Leônidas Helmuth Baebler Hegenberg}

O professor Leônidas Hegenberg nasceu em 14 de março de 1925 na cidade de Curitiba, no Paraná.

Em 1947, ingressou na Faculdade de Filosofia do Instituto Mackenzie, obtendo graus em Matemática e Física. Assim como Nelson Onuchic, também foi aluno do 
professor Francisco Antônio Lacaz Netto, responsável pelo convite para que ingressasse no corpo docente do ITA, em 1950(MORAES, 2007).

Interessado em aprofundar estudos sobre os fundamentos da Matemática, optou pelo curso de Filosofia da Faculdade de Filosofia, Ciências e Letras da USP, realizado entre 1955 e 1958.

No período de 1960 a 1962, tendo recebido uma bolsa da Pan American Union, para estudar como aluno regular na Universidade da Califórnia (Berkeley), teve contato com Paul Feyerabend (1924-1994), que o influenciou sobremaneira na escolha da Filosofia das Ciências como área de pesquisa.

Participou, na USP, de estudos orientados pelo Professor Edison Farah, chegando à conclusão de sua tese de doutorado, intitulada Mudança de Linguagens formalizadas, em 1968.

O professor Leônidas teve sua vida profissional quase ininterruptamente associada ao ITA, de 1950 a 1988 (exceção feita apenas ao período de 1963-1964, em que esteve na Faculdade de Filosofia de Assis), além de ter atuado como professor colaborador e visitante em diversas instituições de ensino como: Faculdade de Engenharia de Guaratinguetá UNESP (1968 - 1970), Pontifícia Universidade Católica (PUC) - São Paulo (1969 - 1975), e Instituto de Pesquisas Espaciais (1973 - 1974 e 1979).

Dentre suas obras, destacam-se Lógica Simbólica (1966), Lógica: o cálculo sentencial (1973), Lógica: o cálculo de predicados (1973), Lógica: simbolização e dedução (1975) e Dicionário de Lógica (1995).

Carvalho $(2012$, p. 2) apresenta o propósito das obras do professor Leônidas: "criar uma filosofia da ciência que superasse o conceito oitocentista de ciência de forte presença na tradição luso-brasileira". Baseando-se nas ideias de David Hume (1711-1776) adotava como único critério de classificação das ciências nos grupos de características formal e factual, apesar de considerar que os tipos de explicação usados nas ciências sociais não se diferenciavam daqueles utilizados em outras ciências.

Os estudos do professor Leônidas tem uma extensão que abrange autores como Russel, Blanché, Carnap, Kuhn, Tarski e Ortega y Gasset.

Além dos livros citados, publicou mais de 50 textos de divulgação em jornais e revistas e traduziu mais de 50 obras, em Filosofia da ciência, Epistemologia e Lógica.

Durante o período de 1965-1977, administrou a publicação da Revista Humanidades, que segundo o diletante idealizador tinha a função de ser

"uma publicação que servisse de veículo para as idéias do pessoal docente e pudesse transformar-se num veículo de difusão de idéias de outras pessoas, ligadas a vida acadêmica, não necessariamente no Brasil e que representasse esse esforço de permuta de publicações". (HEGENBERG, 1987, p. 24).

A publicação desta revista foi encerrada após 12 anos de existência, pois os gastos de produção das matrizes, impressão e correios foram considerados excessivos pela reitoria do ITA. 
Outra atividade exercida com dedicação pelo professor Leônidas foi a redação de comentários de livros, destacado por seu filho em uma constatação a respeito das resenhas publicadas na Revista Brasileira de Filosofia, veículo de comunicação do Instituto Brasileiro de Filosofia, criado pelo jurista Miguel Reale (1910-2006), sociedade da qual Hegenberg foi membro desde 1959.

"Leônidas exerceu a atividade de resenhador da RBF durante pelo menos 45 anos. Em 2002-2003, o IBF publicou um Índice da Revista Brasileira de Filosofia: 1951-2000. Essa publicação - patrocinada pelo Centro de Documentação do Pensamento Brasileiro, com sede em Salvador (Bahia), presidido pela professora Dinorah Berbert de Castro relaciona (ordem cronológica), em 115 páginas, os artigos publicados pela Revista ao longo de seus primeiros 50 anos de existência. Em seguida, 147 páginas são dedicadas a registrar as resenhas publicadas nesses anos. Se não errei a contagem, há 311 resenhas de Leônidas (ao lado de 35 artigos, de importância e tamanho variáveis). "(HEGENBERG, 2007)

Faleceu em 2012, pouco tempo depois de ver publicada mais uma obra sua: Métodos de Pesquisa: de Sócrates a Marx e Popper, escrita em parceria com Antônio Henriques de Araújo Jr. e o filhoFlávio E. N. Hegenberg.

\section{Leo Huet Amaral}

O professor Leo Huet Amaral obteve sua graduação em Matemática pela Pontifícia Universidade Católica - PUC de São Paulo.

Após ingressar no ITA como Auxiliar de Ensino, teve a oportunidade de realizar seus estudos de pós-graduação na Universidade da Califórnia - Berkeley, onde obteve seus títulos de Mestre e Doutor. Seu trabalho de doutoramento, concluído em 1964, teve como título Hypersurfaces in Non-Euclidean Spaces e foi orientado pelo professor ShiingShenChern ${ }^{14}$ (1911-2004)

Foi um dos responsáveis pelas traduções das obras do professor Murnaghan adotadas como textos básicos para os cursos de Matemática. O contato com o professor Murnaghan, a partir de suas produções e suas instruções, o influenciou na forma de exercer a atividade docente, prezando pelo cuidado nas demonstrações dos teoremas apresentados e pela assessoria dedicada aos alunos na resolução de exercícios.

Textos de sua autoria com o apoio do professor Carlos Alberto de Buarque Borges também constituíram a bibliografia de disciplinas dos cursos de graduação do Instituto.Redigiu, também, juntamente com o professor Nelson Onuchic, o texto Álgebra Multilinear e Variedades diferenciáveis no $1^{\circ}$ Colóquio Brasileiro de Matemática, em 1957,

\footnotetext{
${ }^{14}$ O professor Chern também orientou, no ano de 1963, Manfredo Perdigão do Carmo (1928-), na pesquisa The CohomologyRingofCertainKahlerianManifolds. O professor Manfredo é nome importante no Instituto Nacional de Matemática Pura e Aplicada (IMPA).
} 
valendo-se de debates realizados com o professor Chaim Samuel Hönig durante o Encontro e, anteriormente, em um ciclo de seminários que havia sido ministrado aos membros do Departamento de Matemática do ITA. Sobre esta atividade, há um elogio do professor Chaim dirigido ao professor Leo e a outro dos autores, o professor Antonio Rodrigues ${ }^{15}$, dizendo que estes "dedicaram-se com entusiasmo à penosa tarefa da redação dos cursos, para os quais contribuíram com valiosas sugestões e não pouparam esforços para que as redações ficassem prontas em tempo." (HÖNIG, 1957, p. II).

\section{Considerações}

A criação do ITA, no âmbito do CTA, com estruturas acadêmica e administrativa inovadoras demandaram detalhado planejamento. A adoção do modelo do MIT aproveitava as experiências de algumas décadas daquela instituição, em especial no delineamento da grade curricular, do perfil dos ingressantes e da conduta do ensino e pesquisa.

O "espírito" desta instituição norte-americana, desde seu estabelecimento, foi forjado com valores assimilados das modelares instituições de educação tecnológica europeias, valorizando a produção do conhecimento científico atrelado ao desenvolvimento prático e o contato frequente dos docentes com seus pupilos nas diversas etapas da aprendizagem.

Também é marcante no MIT o pioneirismo na criação de cursos conforme as necessidades técnicas da sociedade industrial nascente e o vínculo com as empresas, estabelecendo um auxílio mútuo, em que os industriais investiam no fomento à instrumentação de laboratórios e recebiam, em troca, profissionais altamente capacitados, capazes de promover inovações nas linhas de produção.

Liderado pelo professor Richard Harbert Smith, a equipe que traçou as linhas mestras da fundação do CTA (e, consequentemente, do ITA) reproduziu a ideologia das diversas instituições norte-americanas similares ao MIT, nas recomendações sobre o currículo, dotado de flexibilidade, sobre o corpo docente, com dedicação exclusiva e apoio adequado para o desempenho de suas funções e sobre o objetivo principal: estabelecer uma escola de Engenharia, com ênfase na Aeronáutica que pudesse garantir ao Brasil independência tecnológica e produção industrial nesta área.

Os diversos professores estrangeiros de renomada competência, contratados no início das atividades do Instituto traziam consigo a experiência obtida em universidades, órgãos governamentais e centros de pesquisa da Europa e dos Estados Unidos e, associados aos docentes brasileiros convidados por Montenegro e sua equipe, constituíram um corpo docente capaz de atuar tanto no ambiente acadêmico como no desenvolvimento de pesquisas, além de treinar os docentes mais inexperientes, forjando as características do profissional desejado para atuar nos cursos oferecidos.

A proposição de cursos de pós-graduação, desejo latente desde os primórdios do ITA, possibilitou a capacitação de seus próprios professores, além de ter permitido que

15 Antonio Rodrigues (1918-2003), graduado pela USP e pós-graduado pelo IMPA, foi professor titular do Instituto de Matemática da UFRGS.

RBHM, Vol. 16, n³1, p. 21-49, 2016 
muitos graduados oriundos de outras instituições pudessem obter seus títulos. Especialmente na área de Matemática (Ciências), permitiu a progressão de estudos de dezenas de profissionais que acabaram sendo elementos de referências em diversas instituições de ensino superior (inclusive na UNESP, nos campi de Rio Claro e Guaratinguetá).

Identifica-se a posição do ITA como criador de um dos primeiros programas de Pós-graduação na estrutura que hoje é adotada em todo o país, já que fora moldado conforme os padrões norte-americanos, padrão este adotado pelo MEC após o parecer $\mathrm{n}^{\circ}$ 977 do CFE.

Com apoio nas ideias de Cunha, é impossível negar o impacto que a criação do ITA causou no ambiente acadêmico do país.

A criação do Instituto Tecnológico de Aeronáutica - ITA, em 1947, significou um grande avanço no ensino superior, marcado pela inovação acadêmica e profundamente influenciado pelos padrões de organização universitária dos EUA. [...] A existência do ITA como uma "ilha" de ensino superior moderno num "mar" de escolas arcaicas animou os reformadores do ensino, tanto os que viam na sua modernização o caminho necessário para que o país adquirisse a maioridade científica e tecnológica indispensável, por sua vez, para viabilizar o rompimento dos laços de dependência do exterior quanto os que pretendiam reforçá-los, no intuito de modernizar o país, começando pelo sistema educacional, à imagem do paradigma do país capitalista hegemônico. (CUNHA, 2011, p. 173.)

O desenvolvimento da Matemática no Brasil, bem como o desenvolvimento de uma cultura de excelência acadêmica e científica em várias outras instituições têm, portanto, a participação do ITA a partir das atividades de seus professores e ex-alunos. Afirmamos que foi bastante importante para que Instituto chegasse ao patamar que hoje ocupa o fato de ter contado, em suas fileiras, com profissionais como os professores Murnaghan, Lacaz Netto, Onuchic e Amaral.

O Instituto não foi somente o sonho de Casimiro Montenegro Filho ou o projeto de Richard Harbert Smith, mas foi um elemento constituinte da vida de milhares de brasileiros e estrangeiros que participaram na definição do que foi o ITA no século passado e do que continua sendo até hoje.O espírito das Hochschules, das Polytechniques, absorvido e modificado pela sociedade iluminista norte-americana nas Land-grant instituitions teve, no Brasil, o ITA como berço e polo difusor, atingindo os setores sociais acadêmicos, industriais e científicos.

\section{Bibliografia}


BADIN, Marcelo Gonsalez. Um olhar sobre as contribuições do Professor Nelson Onuchic para o desenvolvimento da Matemática no Brasil.154f. Dissertação (Programa de PósGraduação em Educação Matemática) - Instituto de Geociências e Ciências Exatas de Universidade Estadual Paulista “Julio de Mesquita Filho"IGCE - UNESP, Rio Claro, 2006. BRASIL. Decreto $n^{\circ}$ 27.695, de 16 de janeiro de 1950. Transforma em Curso Fundamental e Curso Profissional do Instituto Tecnológico de Aeronáutico os atuais Curso de Preparação e Curso de Formação de Engenheiros de Aeronáutica, e dá outras providências. Disponível em: <http://www2.camara.leg.br/legin/fed/decret/ 1950-1959/decreto-27695-16-janeiro1950-322400-publicacaooriginal-1-pe.html> Acesso em: 09 set. 2013.

BRASIL. Decreto $n^{o} 34.701$, de 26 de novembro de 1953. Considera organizado o Centro Técnico de Aeronáutica. Disponível em: <http://www2.camara.leg.br/legin/ fed/decret/1950-1959/decreto-34701-26-novembro-1953-328685-publicacaooriginal-1pe.html> Acesso em: 18 jul. 2014.

BRASIL. Lei $n^{\circ} 2.165$, de 05 de janeiro de 1954. Dispõe sobre o ensino superior no Instituto Tecnológico de Aeronáutica. Disponível em: <http://www2.camara.leg.br /legin/fed/lei/1950-1959/lei-2165-5-janeiro-1954-361506-publicacaooriginal-1-pl.html> Acesso em: 15 maio 2013.

BRASIL. Lei $n^{\circ}$ 4.024, 20 dez. 1961. Fixa as Diretrizes e Bases da Educação Nacional. Disponível em: <http://www.planalto.gov.br/ccivil_03/leis/14024.htm> Acesso em: 07 jan. 2013.

BRASIL. Ministério da Aeronáutica. Portaria Interministerial $n^{\circ}$ 18/GM3, 20 fev. 1968. Altera a denominação da Comissão de Pós-graduação do ITA para Curso de Pós-graduação e dá outras providências.

CALABRIA, Angelica Raiz. Acervo do Professor e Matemático Lacaz Netto: uma breve apresentação. Anais do $13^{\circ}$ Seminário Nacional de História da Ciência e da Tecnologia. USP, 2012.

CAMBESES JÚNIOR, Manuel. Marechal do Ar Casimiro Montenegro Filho: um notável brasileiro. Instituto Histórico-Cultural da Aeronáutica (INCAER). s/d. Disponível em: <https://www.incaer.aer.mil.brmontenegrofilho.htm/> Acesso em 04 jun. 2012.

CASSUTO, Leonard. Faculty Immobility in the New Economy.2011. Disponível em $<$ http://chronicle.com/article/Faculty-Immobility-in-the-New/128142/> Acesso em 13 jul 2014.

CONSELHO FEDERAL DE EDUCAÇÃO. Parecer $n^{\circ}$ 977, 03 dez. de 1965. Definição dos cursos de pós-graduação. Disponível em: <http://www.capes.gov.br/ images/stories/download/legislacao/Parecer_CESU_977_1965.pdf>. Acesso em:10 abr. 2013.

CURY, Carlos Roberto Jamil. Quadragésimo ano do parecer CFE no 977/65. In: Revista Brasileira de Educação, n. 30, set.-dez., 2005. p. 7-20.

D’AMBROSIO, Ubiratan. Uma história concisa da Matemática no Brasil. Petrópolis: Vozes, 2011.

GARTENKRAUT, Michal. Memória: Recommendations for the CTA Law (Plano Smith) e Brasil: Futura Potência Aérea- Conferência Proferida pelo Professor Richard H. Smith, no Rio de Janeiro, em 1945 In: Revista Brasileira de Inovação,n. 1, Vol. 7, 2008, p. 209-241. 
HAIN, Richard; TONDEUR, Philippe.The life and work of Kuo-Tsai Chen. In: Illinois Journal of Mathematics. Vol 34, n. 2, jul-set 1990.

HEGENBERG, Leônidas HelmuthBaebler. História da Ciência (Depoimentos orais realizados pelos Arquivos Históricos do CLE/Unicamp. Disponível em: $<$ http://www.cle.unicamp.br/arquivoshistoricos/Audiovisual/Depoimentos_Historal/eleonid as.pdf > Acesso em: 10 maio 2014. Entrevista concedida a Hiro Barros Kumasaka.

HEGENBERG, Flávio Edmundo Novaes (Org.). Resenhas de Leônidas Hegenberg (19982003) Filosofia, Lógica e História. Rio de Janeiro: E-Papers. 2007.

HÖNIG, Chaim Samuel. Álgebra Multilinear e variáveis diferenciáveis. São Paulo, 1957. Instituto Tecnológico de Aeronáutica (ITA).Ata da $3^{a}$ sessão da $11^{a}$ reunião da Congregação. São José dos Campos, 02 nov. 1951. . Ata da $14^{a}$ reunião da Congregação. São José dos Campos, 06 set. 1951.

26 jun. 1952. . Ata da $16^{a}$ reunião da Congregação. São José dos Campos, 05 maio 1952 e . Ata da $34^{a}$ reunião da Congregação. São José dos Campos, 26 ago. 1954. nov. 1956. . Ata da $6^{a}$ sessão da $51^{a}$ reunião da Congregação. São José dos Campos, 22 . Ata da $9^{a}$ sessão da $51^{a}$ reunião da Congregação. São José dos Campos, 07 dez. 1956.

set. 1958 . Ata da $2^{a}$ sessão da $67^{a}$ reunião da Congregação. São José dos Campos, 04 Ata 97 reunião da Congregação. São José dos Campos, 26 abr. 1962.

. Ata 160 reunião da Congregação. São José dos Campos, 29 out. 1964. . Catálogo de cursos de Engenharia. São José dos Campos, 1958. . Informações sôbre o ano letivo de 1951. São José dos Campos, 1950. . Normas Gerais do curso de pós-graduação do ITA. São José dos Campos, 1968.

KERR, Willian Jasper; DAVENPORT, Eugene; BRYAN, Enoch Albert; THOMPSON, Willian Oxley.The Spirit of the Land-grant Instituitions. Forty-fifth Annual Convention of the Association of land-Grant Colleges and Universities at Chicago, III., November 16-18, 1931. Universityof Arizona: Tucson, 1931.

LE GOFF, Jacques. História e memória. Campinas: Editora da Unicamp, 1996.

LEWIS, David W. 'To the glory of God, honour of Ireland and fame of America': a biographical sketch of Francis D. Murnaghan. In: Mathematical Proceedings of the Royal Irish Academy, n. 103, v. 1, 2003, p 101-112.

MASSACHUSETTS INSTITUTE OF TECHNOLOGY.President's Report.vol. 49, $\mathrm{n}$. 2.Massachusetts: MIT Press. 1914.

MONTENEGRO FILHO, Casimiro. Casimiro Montenegro Filho (depoimento, 1988). Rio de Janeiro, CPDOC, 2006. 41 p. Entrevista concedida a Cláudia Maria Cavalcanti de Barros Guimarães e Simon Schwartzman.

MORAES, Carlos Roberto. Uma história da Lógica no Brasil.134f. Tese (Programa de Pós-Graduação em Educação Matemática) - Instituto de Geociências e Ciências Exatas de Universidade Estadual Paulista "Julio de Mesquita Filho"IGCE - UNESP, Rio Claro, 2007. 
MORAIS, Fernando. Montenegro: as aventuras do Marechal que fez uma revolução nos céus do Brasil. São Paulo: Planeta, 2006.

NATIONAL ACADEMY OF ENGINEERING. Memorial Tributes: National Academy of Engineering, Volume 12. Washington, DC: The National Academies Press, 2008. pp. 305308

O' CONNOR, J.J.; ROBERTSON, E. F. Kuo Tsai Chen biography.2007. Disponível em <http://www-history.mcs.st-andrews.ac.uk/Biographies/Chen.html>. Acesso em: 15 jul 2013.

SANTOS, Dominique Vieira Coelho. Acerca do conceito de representação. In: Revista de Teoria da Historia, ano 3, n. 6, dez 2011. Universidade Federal de Goiás. Disponível em: <http://revistadeteoria.historia.ufg.br/up/114/o/Artigo\%202,20SANTOS.pdf? 1325192377> Acesso em: 18 abr. 2014.

SMITH, Richard Harbert. Brasil, futura potência aérea. Rio de Janeiro, 1946.

STRATTON, Julius Adams; MANNIX, Loretta H. Mind and Hand: the birth of MIT. Massachusetts: MIT Press, 2005. 781 p.

TOLEDO, José do Carmo. Uma história do processo de institucionalização da área de Análise Matemática no Brasil. 331 f. Tese (Programa de Pós-Graduação em Educação Matemática) - Instituto de Geociências e Ciências Exatas de Universidade Estadual Paulista "Julio de Mesquita Filho"IGCE - UNESP, Rio Claro, 2008

ESTADOS UNIDOS DA AMÉRICA. Lei 37-108, de 02 jul 1862. Established land grant colleges.Enrolled Acts and Resolutions of Congress, 1789-1996; Record Group 11; General Records of the United States Government; National Archives.

\author{
Henrique Marins de Carvalho \\ Instituto Federal de Educação, Ciência e Tecnologia \\ de São Paulo - IFSP - campus São Paulo - Brasil \\ E-mail:hmarins@ifsp.edu.br
}

